\title{
An evaluative study on comparison of problem based learning and lecture based pedagogy on self directed learning in undergraduate medical education
}

\author{
Srikumar Chakravarthi ${ }^{1}$, John Paul Judson ${ }^{2}$ and Priya Vijayan ${ }^{3}$ \\ ${ }^{1}$ Dept. of Pathology; ${ }^{2}$ Dept. of Human Biology Faculty of Medicine, International Medical University, Malaysia \\ ${ }^{3}$ Educational Psychologist, Global Indian International School, Kuala Lumpur, Malaysia
}

srikumar_chakravarthi@imu.edu.my

\begin{abstract}
This study was done to evaluate and compare the effectiveness of problem-based learning (PBL) with that of lecture based instructional approaches on various facets of students' self directed learning, including motivation and learning strategies. Participants included 96 phase 1 MBBS students instructed by the same facilitators, half of whom were control group. The authors randomly assigned 1 class as the experimental group and the other class as the control group. Lecturers instructed the control group with lecturer-centered, textbookoriented traditional instruction; they exposed the experimental group to problem-based learning, in which students worked with ill-structured problems. Results revealed that PBL students had higher levels of intrinsic goal orientation, task value, use of elaboration learning strategies, critical thinking, metacognitive self-regulation, effort regulation, and peer learning compared with control-group students.
\end{abstract}

Keywords: Science education, medical, problem based learning, self directed learning. Introduction

Over the last decade, the framework for understanding the psychological basis of learning has shifted gradually from a lecture-centered approach to a student-centered approach. That perspective has placed an increasing responsibility on learners for their own learning. The learners become aware of, and reason about, conceptual relations or describe learning as a process of conceptual refinement, and they construct their own conceptualizations and solutions to problems. Hence, students should not depend on teachers to learn; instead, they should be independent learners throughout their lives.

Education research reveals that beliefs and cognition that enable students to be independent learners are related highly to academic learning. That viewpoint has led to an increased emphasis on how classroom context and other contextual factors shape and influence student learning and motivation. Therefore, educators focus their attention on students' strategic efforts to manage achievement through specific beliefs and processes. Those self-directed processes and beliefs have been the focus of systematic research (Zimmerman \& Risemberg, 1997). Efforts made by researchers in the field of educational psychology to define self-directed learning resulted in the description of self-directed learning as the degree to which students metacognitively, motivationally, and behaviorally participate in their learning process.

Sci.Tecnol. Edu.

CIndian Society for Education and Environment (iSee)

"Medical education" http://www.indjst.org
Barry Zimmerman (2002), renowned scholar in the field of self-regulated learning, defined self-regulation as the process that students use to activate and sustain their thoughts, behaviours, and emotions to reach their goals. According to Zimmerman, self-directed students set goals effectively, plan and use strategies to achieve their goals, manage resources, and monitor their progress. From that perspective, the value of self-direction in schools is readily obvious. Students who can initiate learning tasks, set goals, decide on appropriate strategies to achieve their goals, then monitor and evaluate their progress are likely to achieve at higher levels than are students who rely on lecturers to perform these functions. Zimmerman argued that self-directed learners continuously adjust their goals and choices of strategies in response to changing intrapersonal, interpersonal, and contextual conditions.

However, self-directed skills are of little value if students do not motivate themselves to use them. Several self-motivational beliefs form a basis for goal setting and strategic planning. The self-motivational beliefs are self-efficacy, outcome expectations, intrinsic interest or value, and goal orientation. Self-efficacy refers to students' beliefs about their capability to learn or to perform effectively; outcome expectations refer to students' beliefs about the ultimate end of performance. Self-directed learners appear to be self-efficacious about their ability to master a learning task. Research findings reveal that students with a high sense of self-efficacy tend to use cognitive and metacognitive strategies and persist in difficult or uninteresting tasks (Pintrich \& DeGroot, 1990; Dembo \& Eaton, 2000; Neber \& Schommer-Aikins, 2002; Shu-Shen, 2002). Intrinsic interest or value and goal orientation essentially concern students' reasons for performing a task (Pintrich \& DeGroot, 1990; VanderStoep et al., 1996; Zimmerman, 2000).

Two general goal orientations that learners can adapt are (a) learning-goal orientation, which students perceive as important for developing new skills, and, thus, learning and mastering subject material and (b) performance or ability orientation, in which students focus on ability and performance in relation to other students (Wolters et al., 1996). Education researchers have reported that learning-goal orientation and the belief that a task is interesting and important are related positively to reports of cognitive, metacognitive, and self-regulatory strategies, such as elaboration, organization, planning, monitoring, and regulating learning (Ames \& Archer, 1988; Meece et 
al., 1988; Nolen, 1988; Pintrich \& DeGroot, 1990; Neber \& Schommer-Aikins, 2002).

From a social and cognitive perspective, researchers view self-direction as an interaction of personal, behavioural, and environmental triadic, and, simultaneously, cyclic processes. Personal processes involve students' knowledge, metacognitive processes, goals, and effects. Behavioral processes involve selfobservation, self-judgment, and self-reaction. Environmental processes involve enactive outcomes, modeling, and verbal persuasion. Social cognitive theory proposes that those self-regulatory processes and accompanying beliefs are affected by social and physical environments. On the basis of that idea, researchers consider that modeling and instruction are primary vehicles through which self-regulatory skills can be taught (Schunk \& Zimmerman, 1997; Zimmerman, 2002). Researchers also have suggested that problem-based learning (PBL), which places responsibility on students to access information, to achieve goals, and to monitor understanding, can be used by lecturers to support the development of self-regulated learning (Paris \& Paris, 2001; Karabulut, 2002; Perry et al., 2002).

In PBL environments, students act as professionals and are confronted with problems that require them to (a) clearly define an ill-structured problem; (b) develop multiple hypotheses; (c) access, analyze, and use data from different sources; (d) revise the initial hypothesis as data are collected; and (e) develop and justify solutions according to evidence and reasoning (Barrows, 1986; Gallagher et al., 1995). Therefore, students in a problem based classroom must seek information, access learning material, and communicate acquired knowledge to other students and teachers while they work in small groups with ill-structured problems (Rosing, 1997). Results of research on PBL in elementary and high school settings revealed that $\mathrm{PBL}$ creates an environment in which students (a) participate actively in the learning process, (b) take responsibility for their own learning, and (c) become better learners in terms of time-management skills and ability to define topics, access different resources, and evaluate the validity of these resources (Gallagher et al., 1995; Krynock \& Robb, 1996).

Moreover, PBL appears to improve critical thinking, communication, mutual respect, teamwork, and interpersonal skills and increase students' interest in a course (West, 1992; Sage, 1996; Savoie \& Hughes, 1994; Achilles \& Hoover, 1996; Gordon et al., 2001; McBroom \& McBroom, 2001). In PBL classes, students can confront meaningful problems because of their reallife context. When PBL students solve problems, lecturers encourage them to explore possibilities, invent alternative solutions, collaborate with other students, try out ideas and hypotheses, revise their thinking, and, finally, present their best solutions.

Savery and Duffy (1995) pointed out that the focus in $\mathrm{PBL}$ is on students as constructors of knowledge in a context similar to the context in which they use that knowledge. The students are encouraged to think critically and creatively and to monitor their understanding. PBL students have ownership of the problem, and all learning occurs as a result of considering the problem. Facilitation is focused on metacognitive processes. Therefore, PBL allows students to interact with their environment and their peers, which eventually leads to evolvement of knowledge through social negation. Moreover, ill-structured problems encourage students to apply their newly constructed knowledge and to consider alternative points of view and strategies. Hoffman and Ritchie (1997) stated that when students use that approach, problem-based learning can promote transfer of knowledge and skills gained in the school to daily life.

However, there are few studies that provide empirical evidence concerning the effectiveness of PBL on students' self-directed learning (Galand et al., 2003; Lohman \& Finkelstein, 2000). Given the general lack of empirical knowledge concerning the comparative impact of problem-based learning and lecture based instruction on different facets of students' self-directed learning (including motivation and use of learning strategies), three research questions were posed to investigate the effect of PBL in undergraduate medical education: Does PBL affect students' self-reported motivation? Does PBL affect students' self-reported use of learning strategies? Is there a relationship between students' self-reported motivation and self-reported use of learning strategies? Methods

A quasi-experimental design was used in this study; the independent variable was instructional methods (PBL and traditional instruction). The dependent variable was students' scores on each of the subscales of the Motivated Strategies for Learning Questionnaire (MSLQ) (Pintrich et al., 1991) that we used to assess students' self-reported motivation and self-reported use of learning strategies. To address the research questions, two multivariate analyses of variance (MANOVAs) were used: (a) MANOVA for determining the effect of various methods on students' self-reported motivation, as indicated by six subscale scores on the MSLQ and (b) MANOVA for deciding the effect of various methods on students' self-reported use of learning strategies, as indicated by nine subscale scores on the MSLQ. We performed follow-up analyses as needed to evaluate the mean differences between the groups with respect to each dependent variable. Prior to examining multivariate effects, we checked multivariate normality and homogeneity of variance and covariance matrices assumptions of MANOVA. Because one can detect multivariate normality assumption by examining univariate normality of observations on each variable, we conducted the Shapiro-Wilk test (Stevens, 2002). Results revealed that dependent variables were normally distributed across treatment conditions $(p>.05)$. The
Sci.Tecnol. Edu.

CIndian Society for Education and Environment (iSee)
"Medical education" http://www.indjst.org
Srikumar Chakravarthi et al. Indian J.Sci.Technol. 
nonsignificant $F$ tests from Box's $M$ statistics were the sign of homogeneity of variance and covariance matrices $(p>.05)$.

\section{Participants}

Ninety six students from phase 1 MBBS programme of the International Medical University participated in this study, with informed consent. Students were from the PBL groups of various modules classes facilitated by the same two facilitators. We randomly assigned one of the classes as the experimental group $(n=48)$ and the other as the control group $(n=48)$. The mean ages of the students in the experimental group and the control group were 19 years and 19.6 years, respectively. Students came from middle- to upper-class families.

Instrumentation

Students' motivation and use of learning strategies were measured by the MSLQ, which is a self-report questionnaire developed by Pintrich et al. (1991). It consists of two sections, a motivation section and a learning-strategies section, which the researchers designed to determine students' motivational orientations and use of various learning strategies. The motivation section includes 31 items in six subscales that assess students' (a) goals and value beliefs, (b) beliefs about their ability to succeed, and (c) anxiety about tests. The motivation subscales tap into three broad areas:

1. Value components refer to the reasons why students engage in an academic task. Three subscales included in the MSLQ to measure value beliefs include Intrinsic Goal Orientation (a focus on learning and mastery), Extrinsic Goal Orientation (a focus on grades and approval from others), and Task Value (judgments of how interesting, useful, and important course content is to the student).

2. Expectancy components focus on students' beliefs that they can accomplish a task. We constructed two expectancy-related subscales to assess students' Control of Learning Beliefs and Self-Efficacy for Learning and Performance.

3. Affect component refers to students' worry and concerns over taking examinations and includes one subscale, Test Anxiety.

Students' scores on each of the subscales constituted the dependent variables that related to the first research question. We based all subscales on a 7-point scale, ranging from 1 (not at all true of me) to 7 (very true of me). In general, a higher score such as $4,5,6$, or 7 was better than a lower score like 1,2 , or 3 . The only exception was the Test Anxiety scale, where a higher score meant more worrying.

The learning-strategy section of the MSLQ includes 31 items in nine subscales regarding students' use of various cognitive and metacognitive strategies and management of different resources. We based the learning-strategies section on three broad components:

1. Cognitive learning provides a measure of use for Rehearsal (e.g., memorizing lists of keywords), Elaboration (e.g., paraphrasing, summarizing), and
Organization (e.g., outlining). In addition, we included a subscale on Critical Thinking that concerns students' use of strategies to apply previous knowledge to new situations or to make critical evaluations of ideas.

2. Metacognitive strategy consists of one large subscale, Metacognitive Self-Regulation, which assesses the use of strategies that help students control and regulate their own cognition, such as planning, monitoring, and regulating strategies.

3. Resource management includes Time and Study Environment (e.g., using time well, having an appropriate place to study), Effort Regulation (e.g., persisting in the face of a difficult or boring task), Peer Learning (e.g., using a study group or friends to help learn), and Help Seeking (e.g., seeking help from friends or teachers when needed; Pintrich et al., 1993).

Students' scores on each of the nine subscales constituted the dependent variables that were related to the second research question. Scores on each dimension were a measure of how often students use different kinds of study skills and learning strategies.

The MSLQ has been reviewed in the Mental Measurements Yearbook, and content validity has been supported through extensive literature on college students' learning and teaching (Gable, 1998). Although developed for college students, researchers have used the MSLQ successfully with high school students (Barlia \& Beeth, 1999; Higgins, 2000). In the present study, a group of educators and medical university lecturers examined the questionnaire and evaluated its content appropriateness for medical university students. We tested factor validity of the MSLQ subscales by running two confirmatory factor analyses: (a) one analysis for the set of motivation items and (b) an analysis for the set of learning-strategies items.

Two goodness-of-fit statistics that we used in this study were the root mean square error of approximation (RMSEA) and the chi-square and degree of freedom (.2/df) ratio. The RMSEA was based on the analysis of residuals; values below .10 indicated a good fit to the data. We determined the $x^{2}$ ratio by taking the ratio of $x^{2}$ and its degrees of freedom; we determined that $x^{2} / \mathrm{df}$ ratios of less than 5 indicated a good fit to the data (Kelloway, 1998). The RMSEA value and the $x^{2} / \mathrm{df}$ for the motivation section were .09 and 5.3 , respectively. The learning-strategies section of the MSLQ had an RMSEA value of .08 and a $x^{2} / \mathrm{df}$ value of 4.5 . The fit statistics appeared to indicate a good fit. Following factor analyses, we calculated zero-order correlations between the different motivational and cognitive subscales. Moreover, we computed coefficient alpha to assess the internal consistency of the subscales, yielding coefficients ranging from .54 to .89 for the motivation section and from .61 to .81 for the learning-strategy section. In general, subscales correlated with each other in expected directions, and reliability coefficients were reasonable. The original developers (Pintrich et al., 1991) of the
Sci.Tecnol. Edu.

CIndian Society for Education and Environment (iSee)
"Medical education" http://www.indjst.org
Srikumar Chakravarthi et al. Indian J.Sci.Technol. 
MSLQ found similar internal consistency estimates of reliability, ranging from .62 to .93 for the motivation section and from .52 to .80 for the strategy section.

We administered the MSLQ as pretest and posttest to students in experimental and control groups to determine their motivation and use of learning strategies before and after treatment. The lecturer administered the questionnaire to both classes at one time and advised students to (a) complete the questionnaire in its entirety, (b) not discuss their responses with others near them, and (c) be as sincere as possible.

Table 1. Zero order correlation for learning strategies

\begin{tabular}{|l|l|l|l|l|l|l|}
\hline Variable & $\begin{array}{l}\text { Intrinsic } \\
\text { goal } \\
\text { orientation }\end{array}$ & $\begin{array}{l}\text { Extrinsic } \\
\text { goal } \\
\text { orientation }\end{array}$ & $\begin{array}{l}\text { Task } \\
\text { value }\end{array}$ & $\begin{array}{l}\text { Control of } \\
\text { learning } \\
\text { beliefs }\end{array}$ & $\begin{array}{l}\text { Self efficacy } \\
\text { for learning } \\
\text { performance }\end{array}$ & $\begin{array}{l}\text { Test } \\
\text { anxiety }\end{array}$ \\
\hline Rehearsal & $.550^{* *}$ & .174 & $.487^{* *}$ & $.509^{* *}$ & $.365^{* *}$ & .124 \\
\hline Elaboration & $.712^{* *}$ & .114 & $.740^{* *}$ & $.498^{* *}$ & $.571^{* *}$ & .060 \\
\hline Organization & $.618^{* *}$ & .194 & $.574^{* *}$ & $556^{* *}$ & $.445^{* *}$ & .008 \\
\hline Critical thinking & $.644^{* *}$ & .061 & $.668^{* *}$ & $.256^{*}$ & $.558^{* *}$ & .056 \\
\hline Metacognitive self-regulation & $.687^{* *}$ & $.261^{*}$ & $.657^{* *}$ & $.503^{* *}$ & $.550^{* *}$ & .029 \\
\hline Time and study environment & $.567^{* *}$ & .187 & $.691^{* *}$ & $.510^{* *}$ & $.569^{* *}$ & -.096 \\
\hline Effort regulation & $.504^{* *}$ & .202 & $.705^{* *}$ & $.489^{* *}$ & $.542^{* *}$ & .086 \\
\hline Peer learning & $.548^{* *}$ & $.359^{* *}$ & $.479^{* *}$ & $.269^{*}$ & $.287^{*}$ & .242 \\
\hline Help seeking & $.424^{* *}$ & .196 & $.285^{*}$ & .216 & .160 & .121 \\
\hline
\end{tabular}

Treatment

We assigned one class as the experimental group and other class as the control group. The lecturer facilitated the experimental group with PBL. The control group received lecture based instruction. The lecturer covered the topics related to the human reproductive system and the haematology system as part of the regular curriculum. Students in the experimental group and in the control group received identical syllabus-prescribed learning content. The classroom instruction was four 45-min sessions per week. Because the methods of instruction employed in the two groups were implemented by a regular lecturer, the first author trained the lecturer to ensure fidelity of treatment. To that end, the lecturer received a handout that clarified the underlying theoretical background and outlining overview and organization of the implementations.

Because PBL was a novel approach for students in the experimental group, we prepared a similar manual focusing on the description of a typical PBL class to make students familiar with their expected roles. Prior to implementations in the classroom, we fully discussed the manuals with students and the lecturer. After the start of the implementations, we held subsequent meetings with the lecturer to ensure that he was conducting the treatments appropriately in both groups. We contacted the lecturer several times a week to address practical or implementation difficulties and to review the treatment procedure. In addition, we completed classroom observations to document fidelity of the treatment.
Vol.2 No. 12 (Dec. 2009)

ISSN: 0974- 6846
The traditional lecture based instruction involved lessons with lecture and questioning methods to teach the concepts related to the human reproductive system and the haematology system. The students studied the textbooks on their own before the class hour. The lecturer structured the entire class as a unit, and used a powerpoint presentation. The lecturer described and defined the concepts, and, after his explanation, students discussed the concepts with lecturer-directed questions. For the majority of instruction time, students received instruction and engaged in discussions stemming from the lecturer's explanation and questions. Therefore, teaching strategies in the control group relied on lecturer explanation, classic textbooks, and worksheet study within a discussion environment.

Before treatment in the experimental group, we formed five heterogeneous groups $(n=8)$ focusing on learning styles, academic performance, and gender to optimize interaction among students having various characteristics. We determined students' learning styles by administering the Learning Style Inventory developed by Kolb (1985) and categorized students by their performance as high achievers, middle (average) achievers, and low achievers on the lecturer-made biology examinations. The lecturer assigned volunteer roles, such as reader, scribe, doctor, and patient to students in each group. During the treatment, groups dealt with ill-structured problems posed to them as cases from real life. Each case was based on an actual patient. The lecturer distributed seven pages of patient information to students, one page at a time.

The first page contained brief information about the patient, including age, gender, and major complaint. The data presented on subsequent pages included responses to predictable questions related to patient history, possible symptoms, results of laboratory tests, diagnosis, and treatment. The lecturer provided the additional data over time, which allowed for hypothesis generation and for testing every step. The lecturer monitored the group process, remained nondirective, and intervened only to the extent necessary.

In general, the PBL group process, in accordance with the PBL model used by Curry et al. (2001), consisted of three phases. In the first phase, readers read the case while note takers wrote the facts, ideas, hypotheses, and learning issues; facts were listed as they were read. Students then began to discuss the facts to identify as a
Sci.Tecnol. Edu.

CIndian Society for Education and Environment (iSee)
"Medical education" http://www.indjst.org
Srikumar Chakravarthi et al. Indian J.Sci.Technol. 
group which facts were important and which were irrelevant and to probe for scientific explanation. Those steps were accomplished by first using the prior knowledge of the group members. At that point, students had to question whether the information presented was accurate and fully understood. Also, students listed the ideas, generated hypotheses, and identified related learning issues that the group designated as areas in which they had inadequate knowledge for understanding patient events. At the conclusion of each session, the groups decided which learning issues to pursue and which resources to use to gather information. As a final activity of each session, students evaluated their performance individually and as a group. They expressed their opinions about which actions to continue, change, or modify to improve group process.

The lecturer also advised students how to determine learning issues and select and use resources. For example, the lecturer said that learning issues should not be too specific or too general. The lecturer stated that learning issues should be selected in response to the need to answer a question and should be a relatively complete topic representing the body of information within which the answer can be found. Moreover, the lecturer told the students to focus on the underlying basic science rather than on making a diagnosis. Therefore, if students thought that they needed to learn about how kidneys function to better understand a patient's situation, they would identify "basic renal processes" as a learning issue, rather than "tubular reabsorption," because it was more specific to addressing the question under investigation. Lecturers also reminded students that they could bring any books or materials to class to help them work efficiently during group processes. Students could go to the school library and use written, electronic, or human resources.

During the second phase of the PBL group processes, students participated in independent study outside the Table 2. Descriptive statistics for students motivation and use of learning strategies, pretest \& posttest

\begin{tabular}{|c|c|c|c|c|c|c|c|c|}
\hline \multirow[t]{3}{*}{ Variable } & \multicolumn{8}{|c|}{ A. Motivation } \\
\hline & \multicolumn{2}{|c|}{ Pretest control } & \multicolumn{2}{|c|}{ Pretest Exp } & \multicolumn{2}{|c|}{ Post test control } & \multicolumn{2}{|c|}{ Post test exp } \\
\hline & $\mathrm{M}$ & SD & $\mathrm{M}$ & SD & $\mathrm{M}$ & SD & $\mathrm{M}$ & SD \\
\hline Intrinsic goal orientation & 3.34 & 1.22 & 3.65 & 1.15 & 3.65 & 1.42 & 5.20 & 0.85 \\
\hline Extrinsic goal orientation & 4.56 & 1.35 & 4.54 & 1.35 & 4.88 & 0.75 & 5.10 & 0.79 \\
\hline Task value & 4.34 & 1.45 & 4.33 & 1.24 & 4.37 & 1.33 & 5.16 & 1.15 \\
\hline Control of learning belief & 4.65 & 1.05 & 4.83 & 0.88 & 5.32 & 1.08 & 4.89 & 1.22 \\
\hline Self efficacy & 4.32 & 1.17 & 4.09 & 0.74 & 4.99 & 0.12 & 4.77 & 1.05 \\
\hline Test anxiety & 3.98 & 1.33 & 3.88 & 1.25 & 5.30 & 1.26 & 5.10 & 0.95 \\
\hline & \multicolumn{8}{|c|}{ B. Learning strategies } \\
\hline Rehearsal & 3.99 & 1.27 & 3.77 & 1.15 & 4.06 & 1.44 & 5.22 & 0.88 \\
\hline Elaboration & 4.09 & 1.34 & 4.83 & 1.11 & 4.22 & 1.23 & 5.11 & 0.87 \\
\hline Organization & 4.33 & 1.52 & 4.13 & 1.32 & 4.32 & 1.23 & 5.13 & 1.02 \\
\hline Critical thinking & 3.45 & 1.33 & 4.88 & 1.22 & 3.88 & 0.99 & 5.33 & 0.99 \\
\hline Metacognitive self-regulation & 4.03 & 1.15 & 4.33 & 1.11 & 4.65 & 1.12 & 5.28 & 0.93 \\
\hline Time and study environment & 4.05 & 1.12 & 3.99 & 1.22 & 4.60 & 1.23 & 5.00 & 0.66 \\
\hline Effort regulation & 3.92 & 1.34 & 2.96 & 1.13 & 4.65 & 1.15 & 5.24 & 0.75 \\
\hline Peer learning & 3.03 & 1.23 & 4.11 & 1.41 & 3.87 & 1.55 & 4.55 & 0.93 \\
\hline Help seeking & 4.33 & 1.54 & 3.96 & 1.22 & 4.09 & 1.43 & 4.33 & 0.88 \\
\hline \multicolumn{9}{|c|}{$\begin{array}{lc}\text { Sci.Tecnol. Edu. } & \text { "Medical education" } \\
\text { CIndian Society for Education and Environment (iSee) } & \text { http://www.indjst.org }\end{array}$} \\
\hline
\end{tabular}

Results analysis. We used the MSLQ results obtained at the end of the treatment to determine the effect of PBL on students' motivation and use of learning strategies.

The statistical tests were done on students' pretest and posttest scores on the motivation and learningstrategies sections of the MSLQ. MANOVA results, based on pretest scores, revealed no preexisting differences between experimental and control groups with respect to students' self-reported motivation, as indicated by six sub-scale scores, $F(6,52)=1.21$, $\mathrm{p}=.32$, and selfreported use of learning strategies, as indicated by nine subscale scores on the questionnaire, $F(9,49)$ $=0.56, \quad \mathrm{p}=.82$. Therefore, we found that two groups were similar to each other with respect to the collective dependent Indian J.Sci.Technol. 
variable for motivation and use of learning strategies. A nonsignificant Shapiro Wilk test and Box's $M$ test revealed that normality and homogeneity of variance and covariance matrices assumptions of MANOVA were met $(p>.05)$ (Table 1,2).

\section{Effect of PBL on students' self-reported motivation}

The $F$ ratio for MANOVA indicated that the posttest mean scores were statistically significant at the .05 level, $F(6,54)=3.99, p=.002$. That is, the experimental and control groups had statistically significant mean scores on the collective dependent variables of intrinsic goal orientation, extrinsic goal orientation, task value, control of learning beliefs, self-efficacy for learning and performance, and test anxiety. The multivariate eta squared of 0.31 (based on Wilks's lambda) implied that the magnitude of the difference between the groups was not small. That value indicated that $31 \%$ of multivariate variance of the dependent variables was associated with the treatment.

Because we obtained a statistically significant MANOVA $\mathrm{F}$ for the collective dependent variables, we conducted uni-variate ANOVAs to further understand how the two groups would be affected by the interventions regarding each of the dependent variables on posttest scores. A statistically significant mean difference existed between the groups with respect to intrinsic goal orientation and task value $(p<.05)$ When we examined the mean scores, we found that the intrinsic goal orientation of students in the experimental group was higher than that of students in the control groups. Students in the experimental group tended to study medicine for reasons such as challenge, curiosity, and mastery. For instance, although $60 \%$ of students in the experimental group agreed with the statement that "When I have opportunity in this class, I choose course assignments that I can learn from even if they don't guarantee a good grade," the percentage of agreement in the control group was 37.7 when we used the high end of the scale. Moreover, students in the experimental group appeared to perceive medicine as a more interesting, important, and useful course than their other courses because of a high mean score on the task value scale of the MSLQ. That finding also was apparent in the percentage of students who agreed with the statements in the scale. For example, whereas $86 \%$ of students in the experimental group agreed with the statement that "I think the course material in this class is useful for me to learn," only $61.3 \%$ of students in the control group agreed with that statement.

Effect of PBL on students' self-reported use of learning strategies

We conducted MANOVA to determine the effect of PBL on students' self-reported use of learning strategies. We found a statistically significant mean difference between the experimental and the control groups regarding the collective dependent variables of rehearsal, elaboration, organization, critical thinking, metacognitive
Vol.2 No. 12 (Dec. 2009)

ISSN: 0974- 6846 self-regulation, time and study environment, effort regulation, peer learning, and help seeking, $F(9,51)=$ $2.40, p=.002$. On the basis of Wilks's lambda, the multivariate eta squared showed that $30 \%$ of multivariate variance of the dependent variables was associated with the treatment. That finding implied that the magnitude of the difference between the groups was not small.

The univariate ANOVAs for elaboration, critical thinking, metacognitive self-regulation, effort regulation, and peer learning were significant $(p<.05)$. When we examined the mean scores shown, we found that students in the experimental group had higher mean scores on these dependent measures. The experimental group students appeared to use elaboration strategies and metacognitive self-regulatory strategies more than did the control-group students. For example, whereas $70 \%$ of students in the experimental group indicated their agreement with the statement that "I try to apply ideas from course readings in other class activities such as lecture and discussion," only $38.7 \%$ of students in the control group agreed with this statement. We noted similar results regarding agreement with the statement that "I try to think through a topic and decide what I am supposed to learn from it rather than just reading it over when studying": $86.7 \%$ of the experimental group agreed, and only $61.3 \%$ of the control group agreed. In addition, students in the experimental group tended to apply previous knowledge to new situations to solve problems, reach decisions, or make critical evaluations regarding standards of excellence more than did students in the control group, as indicated by their responses on the critical thinking subscale of the MSLQ.

For instance, $60 \%$ of experimental-group students thought the statement that "I treat the course material as a starting point and try to develop my own ideas about it" reflected their thinking. However, only $32.2 \%$ of controlgroup students agreed with the statement. Students in the experimental group also tended to control their effort and attention when there were distractions or difficulties. For example, $83.3 \%$ of students in the experimental group indicated their agreement with the statement that "Even when course materials are dull and uninteresting, I manage to keep working until I finish." However, just $67.8 \%$ of students in the control group agreed with that statement. Students in the experimental group appeared to collaborate with their peers more than did students in the control group. For instance, $80 \%$ of the students in the experimental group thought that the following statement reflected their behaviour: "When studying for this course, I often set aside time to discuss the course material with a group of students from the class." For the control group, $38.7 \%$ of students believed that the statement reflected their behavior.

Furthermore, pre-MSLQ and post-MSLQ scores did not appear to change considerably for students in the control group. However, PBL appeared to improve
Sci.Tecnol. Edu.

CIndian Society for Education and Environment (iSee)
"Medical education" http://www.indjst.org
Srikumar Chakravarthi et al. Indian J.Sci.Technol. 
experimental-group students' use of various learning strategies-intrinsic goal orientation and task value.

Relation between students' self-reported motivation and self-reported use of learning strategies

We computed zero-order correlations to determine the relation among scores on the motivation subscales and learning strategies subscales of the MSLQ. Higher levels of intrinsic goal orientation and task value correlated with higher levels of rehearsal strategy use $(r=.550$ and $r=$ .487 , respectively), elaboration strategy use $(r=.712$ and $r=.740$, respectively), organization strategy use $(r=.618$ and $r=.574$, respectively), critical thinking ( $r=.644$ and $r$ $=.668$, respectively), metacognitive self-regulation $(r=$ .687 and $r=.657$, respectively), management of time and study environment $(r=.567$ and $r=.691$, respectively), effort regulation $(r=.504$ and $r=.705$, respectively), peer learning ( $r=.548$ and $r=.479$, respectively), and help seeking $(r=.285)$. Moreover, higher levels of control of learning beliefs and self-efficacy for learning and performance were related to higher levels of use of all learning strategies except help seeking $(r=.196$ and $r=$ .216, respectively). Extrinsic goal orientation was associated with only metacognitive self-regulation $(r=$ $.261)$ and peer learning $(r=.359)$.

In addition to those results, we found no statistically significant relationship between test anxiety and use of any of the learning strategies. The results, in general, were consistent with findings in the literature: selfefficacy, learning-goal orientation, and the beliefs that the task is interesting and important are related positively to reports of cognitive, metacognitive, and self-regulatory strategies (Ames \& Archer, 1988; Meece et al., 1988; Nolen, 1988; Pintrich \& DeGroot, 1990; Neber \& Schommer Aikins, 2002).

\section{Discussion}

We examined the effect of PBL and lecture based instruction on students' self-reported motivation (intrinsic goal orientation, extrinsic goal orientation, task value, control of learning beliefs, self-efficacy for learning and performance, test anxiety) and self-reported use of learning strategies (rehearsal, elaboration, organization, critical thinking, metacognitive self-regulation, time and study environment, effort regulation, peer learning, help seeking).

Before the treatment, we administered the MSLQ to students in the experimental and control groups to determine whether the groups differed with respect to the collective dependent variables. MANOVA results revealed no preexisting differences between the two groups regarding students' motivation and learning strategies $(p>.05)$. Determining the similarity between students in the experimental and control groups regarding dependent variables was a good starting point for the treatment. Experimental-group students learned PBL, and control-group students received traditional instruction with traditional textbooks. Results revealed that PBL students, more than control-group students, tended to participate in a task for reasons such as challenge, curiosity, and mastery, and they appeared to perceive medicine as interesting, important, and useful.

Gordon and colleagues (2001) similarly found that PBL students value the student-centered nature of PBL, including information seeking, high levels of challenge, group work, and personal relevance of the material. According to Evenson and Hmelo (as cited in Galand et al., 2003), PBL fosters students' motivational beliefs, and self-directed learning strategies. Although we showed that PBL had a positive influence on students' intrinsic goal orientation and task value, it did not affect control of learning beliefs, self-efficacy for learning and performance, and test anxiety perhaps because we implemented PBL in just 6 weeks. That time period might not be adequate for students to develop the beliefs that their efforts to learn will result in positive outcomes (Loyens et al., 2008). Moreover, because PBL was a student centered, novel approach, students might have had concerns about their performance on the examinations, resulting in test anxiety. Post-MSLQ results regarding test anxiety revealed that although not statistically significant; the scores of experimental-group students were higher than were those of control-group students, indicating a higher level of test anxiety in the PBL group. Regarding learning strategies, we found that PBL enhances students' use of elaboration strategies, critical thinking, metacognitive self-regulation, effort regulation, and peer learning. Galand and colleagues (2003) showed that PBL students use more deepprocessing strategies (especially criticizing) and fewer surface-processing strategies (especially rehearsing). Furthermore, the researchers reported that PBL students use more adaptive strategies (especially information searching and monitoring) than do students from a traditional curriculum. As indicated by students' responses to the MSLQ, PBL students used cognitive strategies, such as paraphrasing, summarizing, and generative note taking, which helped them integrate and connect new information, more than did control-group students. Moreover, the extent to which students applied previous knowledge to new situations to solve problems and reach decisions was higher for PBL students than for control-group students. In addition, PBL students appeared to use metacognitive self-regulatory activities, such as planning and monitoring, more than did controlgroup students.

Glaser (as cited in Karabulut, 2002) claimed that PBL students analyze and discuss problems so that they can (a) realize gaps in their knowledge base, (b) determine their strengths and weaknesses, (c) control their own learning, and (d) develop self-directed learning skills. According to Perry and colleagues (2002), students engage in self-directed learning in classrooms where they (a) receive opportunities to participate in complex, openended activities, (b) make choices that influence their learning, and (c) evaluate themselves and others.
Sci.Tecnol. Edu.

CIndian Society for Education and Environment (iSee)
"Medical education" http://www.indjst.org
Srikumar Chakravarthi et al. Indian J.Sci.Technol. 
Moreover, the researchers reported that because of instrumental support that lecturers provided through questioning, clarifying, correcting, elaborating, modeling, and creating an environment in which students can support one another through collaborating, sharing ideas, and problem solving, students demonstrated attitudes and actions expected from independent, academically effective learners-metacognition, intrinsic motivation, and strategic action.

According to Karabulut (2002), PBL creates an environment in which students actively participate in the learning process, take responsibility for their own learning, and become better learners in terms of time management skills and ability to identify learning issues and to access resources. Perry and colleagues proposed that one of the characteristics of PBL classes contributing to self-regulated learning is cooperation among students working in small groups. In the present study, student responses to the MSLQ revealed that PBL students tended to cooperate with their peers and to appreciate the importance of cooperation more than did the controlgroup students; informal talks with students verified this finding. Most of the students indicated that while discussing and listening to their friends in the PBL groups, they revised their ideas and realized the deficiencies in their thoughts. That was a metacognitive process that helped students reflects on their thinking.

King (2002) claimed that some peer-learning tasks, such as (a) working together to solve ill-structured problems, (b) working on problems with several possible solutions, (c) analyzing and integrating ideas that reach beyond presented material to build new knowledge, (d) making decisions within groups, and (e) assessing learning demand a highly complex level of cognitive processing. We propose that presentations made at the beginning of each PBL session and student reports regarding what they learned as a result of PBL activity in relation to the patient's case further helped students monitor their learning, evaluate themselves, and set goals for further learning. In those reports, students critically reviewed the information about the patient, revised their hypotheses continuously, and presented their opinions about the problem on the basis of their previous knowledge, as well as new knowledge acquired from independent study.

According to Torp and Sage (1998), the reflective nature of debriefing is a metacognitive examination of solutions and loose ends, thinking back along the path of the student journey. Paris and Paris (2001) claimed that PBL, which places responsibility on students to (a) find information, (b) coordinate actions and persons, (c) realize goals, and (d) monitor understanding can be used by teachers to support the development of self-regulated learning. That development is important because students who can initiate learning tasks, set their goals, decide on appropriate strategies for setting goals, then monitor and evaluate their own progress are likely to achieve at higher levels than are students who rely on teachers to perform these functions (Risemberg \& Zimmerman, 1992).

Our results revealed that PBL enhances the selfdirected learning skills of phase 1 undergraduate medicine students. Therefore, we suggest that lecturers in undergraduate medicine programmes use PBL to improve students' academic performance by going beyond teaching content to teaching students how to learn. PBL is different from other instructional strategies because it places students in the center of an authentic, ill-structured problem with no correct answer (Sage, 1996; Miflin, 2004). The problem stimulates students to carryout investigations to satisfy their need to know, then links the new knowledge into their thinking and decision making processes (Gordon et al., 2001). Therefore, as students struggle with a problem, they develop the skill to critically evaluate and acquire new knowledge, and attain a commitment to life-long learning (Curry, 2002).

Although we did not intend to investigate the effect of PBL instruction on students' academic achievement along with their self-directed learning skills, we suggest this focus as a next step for further study.

\section{References}

1. Achilles CM and Hoover SP (1996 November) Exploring problem-based learning (PBL) in grades 6-12. Paper presented at the annual meeting of the Mid-South Educational Res. Asso., Tuscaloosa, AL.

2. Ames C and Archer J (1988) Achievement goals in the classroom: Student learning strategies and motivation processes. J. Edu. Psychol. 80, 260-267.

3. Barlia L and Beeth ME (1999 March) High school students' motivation to engage in conceptual change learning in science. Paper presented at the Annual Meeting of the National Asso. for Res. in Sci. Teaching, Boston.

4. Barrows HS (1986) A taxonomy of problem-based learning methods. Med. Edu. 20, 481-486.

5. Curry JJ (2002) Problem-based learning pathway student handbook. Columbus: The Ohio State University, College of Medicine and Public Health.

6. Curry JJ, Lubbers JA and Tijoe SA (2001) A "multisession" problem based learning case for first-year medical students focusing on spontaneous pnemothorax. The J. Clinical Problem Based Learning. 5, 40-63.

7. Dembo MH and Eaton MJ (2000) Self-regulation of academic learning in middle-level schools. The Elementary School J. 100, 473-490.

8. Gable R K (1998) Review of motivated strategies for learning questionnaire. In: The 13th mental measurements yearbook (eds.: Impara J \& Plake, Lincoln BS), The Univ. of Nebraska Press. pp: 681-682.

9. Galand B, Bentein B, Bourgeois K and Frenay EM (2003, August). The effect of PBL curriculum on students' motivation and self-regulation. Paper presented at the Biennial Conf. of the Eur. Asso. for Res. on Learning \& Instruction, Padova, Italy.

10. Gallagher, S. A., Stepian, W. J., Sher, B. T., \& Workman, D. (1995). Implementing problem-based learning in science classrooms. School Sci. \& Maths, 95, 136-146.
Sci.Tecnol. Edu.

CCIndian Society for Education and Environment (iSee)
"Medical education" http://www.indjst.org
Srikumar Chakravarthi et al. Indian J.Sci.Technol. 
11. Gordon PR, Rogers AM, Comfort M, Gavula N and McGee BP (2001) A taste of problem-based learning increases achievement of urban minority middle-school students. Edu. Horizons. 79, 171-175.

12. Higgins BA (2000) An analysis of the effects of integrated instruction of metacognitive and study skills upon the selfefficacy and achievement of male and female students. Master's Res. Project, Miami University, Oxford, Ohio.

13. Hoffman, B and Ritchie D (1997) Using multimedia to overcome the problems with problem-based learning. Instructional Sci. 25, 97-115.

14. Karabulut US (2002) Curricular elements of problembased learning that cause developments of self-directed learning behaviors among students and its implications on elementary education. Doctoral dissertation, The University of Tennessee, Knoxville.

15. Kelloway EK (1998) Using LISREL for structural equation modeling. Thousand Oaks, CA: Sage.

16. King A (2002) Structuring peer interaction to promote high-level cognitive processing. Theory In to Practice, 41, 33-38.

17. Kolb DA (1985) Learning style inventory: Self-scoring inventory and interpretation booklet. Boston: McBer.

18. Krynock KB and Robb L (1996) Is problem-based learning a problem for your curriculum? Illinois School $R \&$ $D$ J. 33, 21-24.

19. Lohman MC and Finkelstein M (2000) Designing groups in problem-based learning to promote problem-solving skills and self-directedness. Instructional Sci. 28, 291-307.

20. Loyens SMM, Magda J and Rikers RMJP 2008) Selfdirected learning in problem-based learning and its relationships with self-regulated learning. Edu. Psychol. Rev. 12, 411-427.

21. McBroom DG and McBroom WH (2001) Teaching molecular genetics to secondary students: An illustration and evaluation using problem-based learning. The Problem Log. 6, 2-4.

22. Meece J, Blumenfeld P and Hoyle R (1988) Students' goal orientation and cognitive engagement in classroom activities. J. Edu. Psychol. 80, 514-523.

23. Miflin B (2004) Adult learning, self-directed learning and problem-based learning: deconstructing the connections. Teaching in Hr. Edu. 9, (1), 43-53.

24. Neber $H$ and Schommer-Aikins M (2002) Self-regulated science learning with highly gifted students: The role of cognitive, motivational, epistemological, and environmental variables. High Ability Studies. 13, 59-74.

25. Nolen S (1988) Reasons for studying: Motivational orientations and study strategies. Cognition \& Instruction. 5, 269-287.

26. Paris SC and Paris AH (2001) Classroom applications of research on self-regulated learning. Edu. Psychol. 36, 89101.

27. Perry NE, Vandekamp KO, Mercer LK and Nordby CJ (2002) Investigating teacher-student interactions that foster self-regulated learning. Edu. Psychol. 37, 5-15.

28. Pintrich PR (2000) The role of goal orientation in selfregulated learning. In: Handbook of self-regulation, (eds.: Boekaert M, Pintrich PR \& Zeidner M), San Diego, CA: Acad. Press. pp: 452-502.
29. Pintrich PR and De Groot E (1990) Motivational and selfregulated learning components of classroom academic performance. J. Edu. Psychol. 82, 33-40.

30. Pintrich PR, Smith DAF, Garcia T and Mckeachie WJ (1991) A manual for the use of the motivated strategies for learning questionnaire (MSLQ). Ann Arbor: The Univ. of Michigan, National Center for Res. to Improve Postsecondary Teaching \& Learning.

31. Pintrich PR, Smith, D. A. F., Garcia, T., \& McKeachie, W. J. (1993). Predictive validity and reliability of the Motivated Strategies for Learning Questionnaire. Educational and Psychological Measurement, 53, 801-81

32. Risemberg R and Zimmerman BJ (1992) Self-regulated learning in gifted students. Roeper Review. 15, 98-101.

33. Rosing J (1997) Teaching biochemistry at a medical faculty with a problem based learning system. Biochem. Edu. 25, 71-74.

34. Sage SM (1996, April) A qualitative examination of problem-based learning at the K-8 level: Preliminary findings. Paper presented at the annual meeting of the Am. Edu. Res. Asso., NY.

35. Savery JR and Duffy TM (1995) Problem-based learning: An instructional model and its constructivist framework. Edu. Technol. 35, 31-38.

36. Savoie JM and Hughes AS (1994) Problem-based learning as classroom solution. Edu. Leadership. 52, 5457.

37. Schunk DH and Zimmerman BJ (1997) Social origins of self-regulatory competence. Edu. Psychol. 32, 195-208.

38. Shu-Shen $S$ (2002) Children's self-efficacy beliefs, goal setting behaviors, and self-regulated learning. J. National Taipei Teachers College. 15, 263-282.

39. Stevens J (2002) Applied multivariate statistics for the social sciences. Mahwah, NJ: Erlbaum.

40. Torp L and Sage S (1998) Problems as possibilities: Problem-based learning for K-12 education. Alexandria, VA: Asso. for Supervision \& Curr. Devpt.

41. VanderStoep SW, Pintrich PR and Fagerlin A (1996) Disciplinary differences in self-regulated learning in college students. Contemporary Edu. Psychol. 21, 345362.

42. West SA (1992) Problem-based learning-A viable addition for secondary school science. School Sci. Rev. 73, 47-55.

43. Wolters CA, Yu SY and Pintrich PR (1996) The relation between goal orientation and students' motivational beliefs and self-regulated learning. Learning \& Individual Differences. 8, 211-238.

44. Zimmerman BJ (2000) Attaining self-regulation. In: (Eds.: Kaerts M, Pintrich PR \& Zeidner M), Handbook of selfregulation, San Diego, CA: Academic Press. pp: 13-39.

45. Zimmerman BJ (2002) Becoming a self-regulated learner: An overview. Theory Into Practice, 41, 64-70.

46. Zimmerman BJ and Risemberg R (1997) Self-regulatory dimensions of academic learning and motivation. In: Handbook of academic learning: Construction of knowledge (Ed.: Phye GD). San Diego, CA: Academic Press. pp: 105-123.
Sci.Tecnol. Edu.

CIndian Society for Education and Environment (iSee)
"Medical education" http://www.indjst.org
Srikumar Chakravarthi et al. Indian J.Sci.Technol. 